\title{
Successful outcome in a perplexing case of Roberts uterus: a rare uterine anomaly, a rare case report with review of literature
}

\author{
Swati Singh, Renuka Malik*, Pooja Gupta, Anjum Ara
}

Department of Obstetrics and Gynecology, ABVIMS and RML Hospital, New Delhi, India

Received: 31 October 2019

Accepted: 28 November 2019

\section{*Correspondence:}

Dr. Renuka Malik,

E-mail: renucam@yahoo.co.in

Copyright: (C) the author(s), publisher and licensee Medip Academy. This is an open-access article distributed under the terms of the Creative Commons Attribution Non-Commercial License, which permits unrestricted non-commercial use, distribution, and reproduction in any medium, provided the original work is properly cited.

\begin{abstract}
Robert uterus is a rare Mullerian development anomaly with very few cases reports available. It presents with triad of morphologic features of - Blind hemi cavity with or without unilateral hematometra, contralateral unicornuate uterine cavity and normal uterine fundus with or without small external indentation. The major difficulty lies in making the diagnosis of Robert's uterus. All the reported cases of Robert's uterus have been managed differently according to patient's complaints. A 25-year-old married female, resident of Agra presented to gynecology OPD of Dr RML Hospital and associated PGIMER in June 2013, with primary infertility and cyclical left sided dysmenorrhoea since menarche. Patient was consulting at her hometown Agra for 2 years and had an USG and MRI pelvis report of Feb. 2013 with her showing unicornuate uterus with rudimentary horn. Infertility investigations were done in our hospital. HSG report was of localized spill on right with left tubal block. Patient was posted for diagnostic hystero-laproscopy which was further followed by laprotomy, after which we could reach to a diagnosis of Robert uterus with noncommunicating left cavity and with severe endometriosis. Patient needed a second hysteroscopy for lysis of septum and subsequently conceived with IVF. She delivered a healthy male baby of $2.65 \mathrm{~kg}$ by elective LSCS at 37 weeks with associated breech presentation with gestational hypertension with severe IHCP on 20 June 2019. Paediatric surgeons and gynecologists should be aware of this rare atypical obstructive Mullerian malformation and its management to avoid inappropriate management delays in these patients. A timely diagnosis and definite treatment have a great impact on future reproductive and endocrine function.
\end{abstract}

Keywords: Hysteroscopic resection, Mullerian anomaly, Robert's uterus, Septate uterus, Tomkins metroplasty, Unilateral dysmenorrhoea

\section{INTRODUCTION}

Robert's uterus is a rare type of mullerian development anomaly classified as Class VB; a variant of septate uterus (American Fertility Society classification of uterovaginal anomalies). ${ }^{1}$ Its reported incidence is 0.1 $3.5 \%$. $^{2}$ It is also known as asymmetric septate uterus and was first reported by Robert in $1970 .^{3}$ This condition is recognized by presence of uterine septum dividing the endometrial cavity asymmetrically resulting in a non- communicating hemi uterus causing obstruction to menstrual flow in one cavity, resulting in hematometra, haematosalpinx and sometimes endometriosis. ${ }^{4}$ Robert's uterus can act as structural and functional features of two classes of malformation unicornuate and septate uterus. There is a triad of morphologic features of Robert's uterus - Blind hemi cavity with or without unilateral hematometra, contralateral unicornuate uterine cavity and normal uterine fundus with or without small external indentation. Awareness of this rare anomaly can prevent 
the dilemma associated with its diagnosis and management.

\section{CASE REPORT}

Mrs. X, a 25-year-old married female, housewife resident of Agra presented to gynae OPD of RML Hospital, New Delhi with primary infertility in June 2013.Her preliminary work up for infertility was not done apart from USG and MRI. The imaging studies showed a unicornuate uterus with a left sided rudimentary horn. Patient gave history of cyclical left sided dysmenorrhea since menarche. Pain had become recurrent, progressively severe and associated with vomiting since a year. The infertility work up was done. Husband semen analysis was normal. EB was reported as secretory endometrium and TB PCR was negative. HSG was reported as localized spill on right with left tubal block. Patient was taken for diagnostic hystero-laproscopy on 11 November 2013. Hysteroscopy showed single cervix with normal looking uterine cavity. Right ostia was seen, left ostia was not seen and a white fibrous band due to which lower end could be visualized on left side (Figure 1).

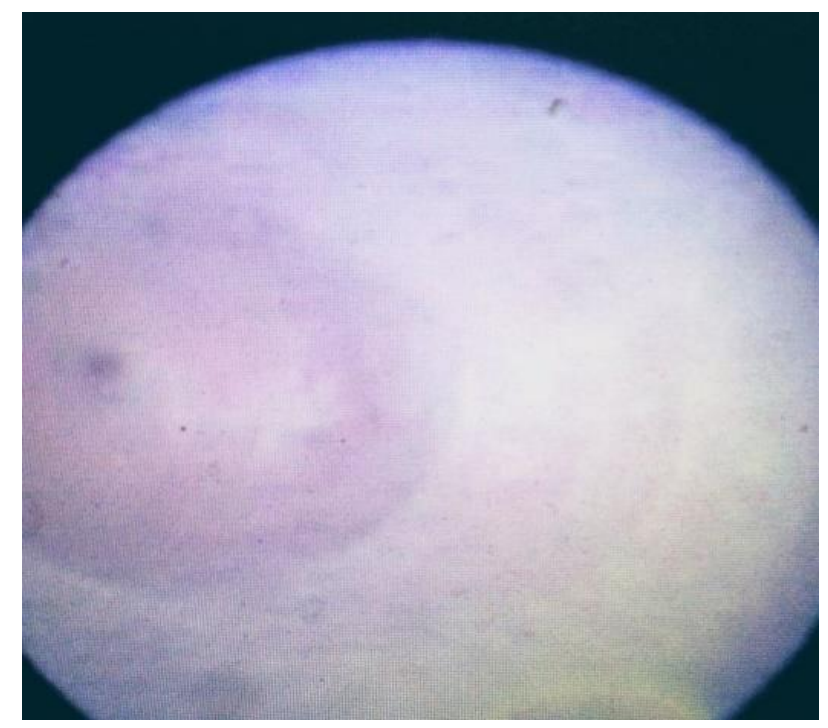

Figure 1: Hysteroscopic view: right ostia seen. Left ostia not visualized covered with fibrous tissue.

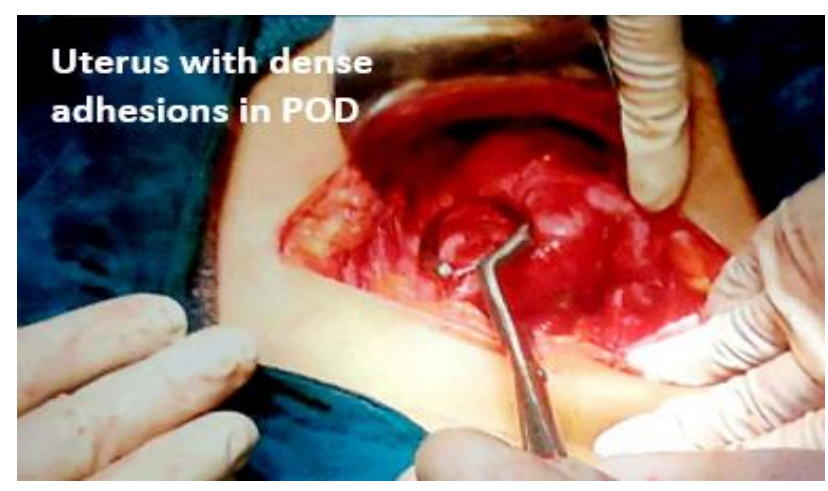

Figure 2: Endometriotic dense adhesions and fixed uterus at laparotomy.

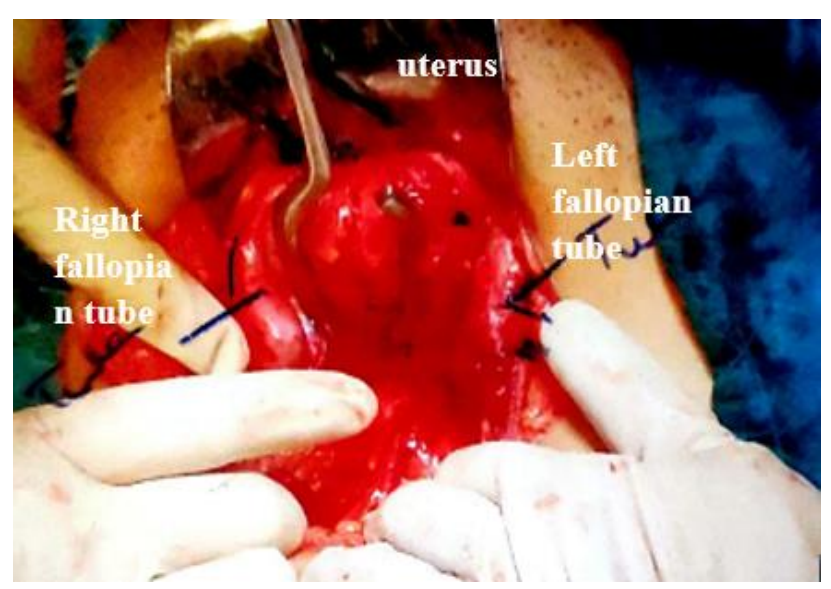

Figure 3: Normal contour of uterus revealed after adhesiolysis.

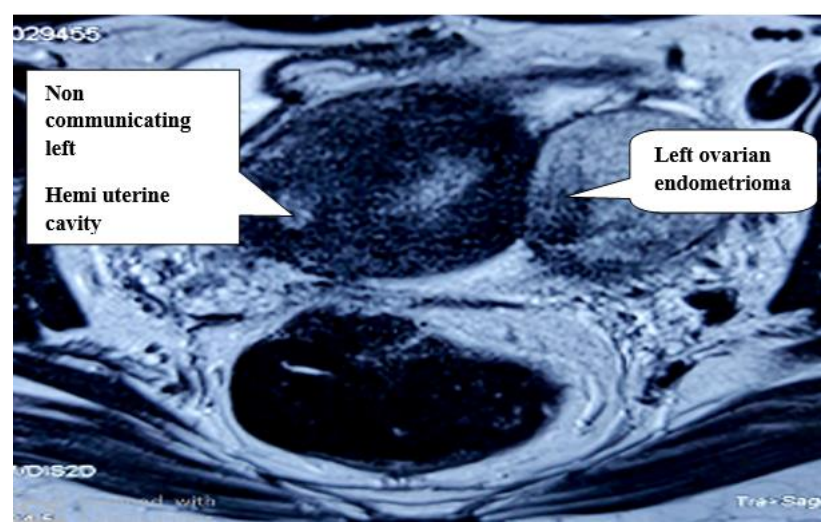

Figure 4: MRI prior to second look hysteroscopy followed by septa resection.

At laparoscopy dense adhesions with presence of endometriotic deposits on left side, uterus was buried deep in pelvis and could be identified only by hysteroscopic light introduced from below. A decision to convert to laprotomy was taken. At laprotomy, uterus was fixed deep in pelvis, adhesiolysis was done to reveal a normal fundus with normal fallopian tubes bilaterally. There was no distension on left side of uterus as the hematometra was minimal. No evidence of the expected rudimentary horn seen on left side. POD which was obliterated due to endometriotic deposits (Figure 2). Bilateral ovaries could not be seen as they were buried in endometriotic adhesions. After adhesiolysis was done, a normal uterine fundus was revealed with buried adherent ovaries in pouch of Douglas which were freed as much as possible (Figure 3). Chromopertubation revealed minimal spill in right tube. The findings left us perplexed at that time to the best course of action. Endometrial resection and metroplasty versus repeat attempt at hysteroscopic resection were contemplated. Abdominal metroplasty was not decided as uterine cavity did not appear very small despite fibrosis on left. After much deliberation patient was offered repeat hysteroscopy for lysis of septum followed by IVF and patient was closed with diagnosis of septate uterus with endometriosis. Patient went back to 
her home town in Agra and decided to take further treatment from there. She took GnRH injections for 3 months and was planned for hysteroscopic resection. In the intervening 4 years, patient tried for hysteroscopy at her home town Agra but had financial constraints. She came back after 4 years to Delhi for treatment in February 2018. A repeat MRI of pelvis (Figure 4) and abdomen was done which now was consistent with our diagnosis of endometriosis with septate uterus. However, the volume of left hematometra was small reported as 4 $\mathrm{ml}$. She underwent hysteroscopic resection in feb2018 and went in for IVF. Luckily she conceived in first cycle of IVF, which was done in a private centre in Delhi in October 2018 and reported back to us. A prophylactic encirclage was done at 11 weeks POG. Her pregnancy was monitored carefully for preterm labor and IUGR. At 34 weeks POG she developed gestational hypertension and was started on Tab. labetalol $100 \mathrm{mg}$ BD. Later at 35 weeks POG she also developed IHCP and was given Tab ursodeoxycholic acid $300 \mathrm{mg}$ BD. She also had persistent Breech presentation. LSCS was done at 37 weeks+1 day and a healthy male baby of $2.65 \mathrm{~kg}$ was delivered. During caesarean dense adhesions were present. Both tubes and ovaries were buried in adhesions. POD was obliterated and adhered with intestines. After delivery of baby, uterine cavity was explored, which felt grossly normal from inside, with no evidence of septa. She had an uneventful post-operative recovery. At her 3 months follow-up mother and child were heathy; mother was in lactational amenorrhea and had received depot provera for contraception and also to help her remain pain free because of her residual endometriosis.

\section{DISCUSSION}

Robert's uterus is a rare type of mullerian development anomaly classified as Class VB, a variant of septate uterus with very few cases being reported. Its prevalence has been underestimated due to misdiagnosis. It presents with two cavities, one of which is blind containing retained secretions and presenting with severe dysmenorrhoea and unilateral hematometra soon after menarche. It is usually accompanied by haematosalpinx and endometriosis.

Robert's uterus is difficult to diagnose preoperatively and is often misdiagnosed. Diagnostic modalities may include ultrasound, hysterosalpingography (HSG) and magnetic resonance imaging. Ultrasound sensitivity for diagnosis of Robert's uterus is not high and frequently misdiagnosed as unicornuate uterus with noncommunicating rudimentary horn, as in our case. Incidence of Rudimentary horn is $26 \%$ and diagnosis before symptom presentation is made in only $14 \%$ cases. ${ }^{5}$ Since significant limitations remain in diagnosing certain mullerian anomalies subtypes on ultrasound MRI is the preferred method of imaging as it is capable of showing the endometrial cavity and uterine contour in exquisite detail.6,7 MRI provides excellent tissue characterization helping in reliably differentiating septate from bicornuate uterus and also in diagnosing asymmetric septate uterus and is the gold standard investigation. ${ }^{7-10}$ However we were not helped by MRI which was reported as rudimentary horn, which is also a differential diagnosis in any patient presenting with unilateral dysmenorrhoea. The main point to differentiate Robert's uterus from rudimentary uterine horn is laparoscopic appearance: the former usually has normal uterine shape (a fundal contour that is convex, flat, or has a small indentation $(<1 \mathrm{~cm})$, but the latter has the fundal cleft be greater than $1 \mathrm{~cm}$ like bicornuate uterus. 3D USG can also be used in differential diagnosis, surgical planning and postoperative assessment of case of Robert's uterus. It is important to make early diagnosis as retrograde menstruation led to high stage endometriosis and infertility as in our case. A rare complication of Robert's uterus is pregnancy in the non-communicating half of the uterus caused by trans peritoneal migration of sperms. ${ }^{11}$

Roberts's uterus is a uterine anomaly, diagnosis and management of which is encountered only in case reports. Review of available literature on Roberts's uterus was done using Pub med, Medline and Google search engines and a total of 14 case reports retrieved. Various management were done in these cases from metroplasty to laparoscopic excision to hysteroscopic resection. Robert's uterus can be managed by laparoscopy /laprotomy and total horn resection or endometrectomy of blinded cavity, Tompkins abdominal metroplasty, or by combining hysteroscopy/laparoscopy or by hysteroscopic resection. At present the modality is best treated by hysteroscopic resection. Surgeries like horn resection/endometrectomy of blinded cavity are associated with loss of the uterine volume. Capito, et al performed an endometrectomy of the blind cavity for a 15 -year-old patient complaining of recurrent abdominal cramps. ${ }^{1}$ In 2003, Singhal reported a rare case of a woman with 26 weeks gestation in asymmetric blind hemi cavity of Robert's uterus, hysterotomy followed by extraction of stillborn fetus of $500 \mathrm{~g}$ was done, and ipsilateral tubal ligation was performed successfully. ${ }^{12}$ This case also suggested possible transfer of the sperm between fimbria across the pouch of Douglas. Tompkins metroplasty was done for this condition.

Ludwin A et al, first reported treatment of Robert's uterus used 3D sonohysterography without laparoscopy or laprotomy. The 3D sonohysterography performed a hysteroscopic metroplasty guided by transrectal ultrasound, avoiding laprotomy/laparoscopy. The treatment result was satisfactory: the menstruation ceased to be painful and resulted in a normalized uterine cavity of $3.6 \mathrm{~cm}^{3}$ from a communicating hemi cavity of $0.3 \mathrm{~cm}^{3}$ after two hysteroscopic procedures. ${ }^{13} \mathrm{Li}$ et al and Sardeshpande $\mathrm{N}$ performed a septum resection with hysteroscopy under ultrasonic surveillance followed by successful pregnancy outcome. ${ }^{14,15}$ Vural et al performed hysterotomy incision and endometrectomy for a Robert's uterus and the patient had a successful pregnancy and delivered a healthy baby by caesarean section in the $39^{\text {th }}$ 
week of gestation. $^{16}$ Hysteroscopic septal resection/metroplasy combined with ultrasound and/or laparoscopy may be a better method for the diagnosis and treatment of Robert's uterus.

\section{CONCLUSION}

Pediatric surgeons and gynecologists should be aware of this rare atypical obstructive mullerian malformation and its management to avoid inappropriate management delays in these patients. A timely diagnosis and definite treatment have a great impact on future reproductive and endocrine function.

\section{Funding: No funding sources}

Conflict of interest: None declared

Ethical approval: No required

\section{REFERENCES}

1. Capito C, Sarnacki S. Menstrual retention in a Robert's uterus. J Pediatr Adolesc Gynecol. 2009;22(5):e104-6.

2. Benzineb N, Bellasfar M, Merchaoui J, Sfar R. Robert's uterus with menstrual retention in the blind cavity. J Gynaecol Obstet Biol Reprod. 1993;22(4):366-8.

3. Gupta N, Mittal S, Dadhwal V, Misra R. A unique congenital mullerian anomaly: Robert's uterus. Arch Gynecol Obstet. 2007;276(6):641-3.

4. Benzineb N, Bellasfar M, Merchaoui J, Sfar R. Robert's uterus with menstrual retention in the blind cavity. J Gynecol Obstet Biol Repro. 1993;22(4):366-8.

5. Jayasinghe Y, Rane A, Stalewski H, Grover S. The presentation and early diagnosis of the rudimentary uterine horn. Obstet Gynecol. 2005;105:1456-67.

6. Acién P. Incidence of Müllerian defects in fertile and infertile women. Hum Reprod. 1997;12(7):1372-6.

7. Behr SC, Courtier JL, Qayyum A. Imaging of müllerian duct anomalies. Radiograph. 2012;32:E233-50.
8. Marcal L, Nothaft MA, Coelho F, Volpato R, Iyer R. Mullerian duct anomalies: MR imaging. Abdom Imaging. 2011;36(6):756-64.

9. Bermejo C, Ten MP, Cantarero R, Diaz D, Pérez Pedregosa J, Barrón E. Three-dimensional ultrasound in the diagnosis of Mullerian duct anomalies and concordance with magnetic resonance imaging. Ultrasound Obstet Gynecol. 2010;35(5):593-601.

10. Maddukuri SB, Karegowda LH, Prakashini K, Kantipudi S. Robert's uterus: a rare congenital müllerian duct anomaly causing haematometra. Case Reports. 2014;2014:bcr2014204489.

11. Chandra M, Pathak V. Pregnancy in noncommunicating half of septate uterus. J Obstet Gynaecol India. 2012;62(Suppl 1):31.

12. Singhal S, Agarwal U, Sharma D, Sirohiwal D. Pregnancy in asymmetric blind hemi cavity of Robert's uterus--a previously unreported phenomenon. Eur J Obstet Gynecol Reprod Biol. 2003;107:93-5.

13. Ludwin A, Ludwin I, Bhagavath B, Lindheim SR. Pre-, intra-, and postoperative management of Robert's uterus. Fert Ster. 2018;110(4):778-9.

14. Li J, Yu W, Wang M, Feng LM. Hysteroscopic treatment of Robert's uterus with laparoscopy. J Obstet Gynaecol Res. 2015;41:1491-4.

15. Sardeshpande N, Chipalkatti P, Doctor J. Roberts uterus: a rare congenital anomaly. Int $\mathrm{J}$ Reprod Contracept Obstet Gynecol. 2017;6:5657-9.

16. Vural M, Yildiz S, Cece H, Camuzcuoglu $\mathrm{H}$. Favourable pregnancy outcome after endometrectomy for a Robert's uterus. J Obstet Gynaecol. 2011;31(7):668-9.

Cite this article as: Singh S, Malik R, Gupta P, Ara A. Successful outcome in a perplexing case of Roberts uterus: a rare uterine anomaly, a rare case report with review of literature. Int J Reprod Contracept Obstet Gynecol 2020;9:440-3. 